\title{
Effects of absorbing aerosols in cloudy skies: a satellite study over the Atlantic Ocean
}

\author{
K. Peters ${ }^{1,2,3}$, J. Quaas ${ }^{1}$, and N. Bellouin ${ }^{4}$ \\ ${ }^{1}$ Max Planck Institute for Meteorology, Hamburg, Germany \\ ${ }^{2}$ University of Hamburg, Hamburg, Germany \\ ${ }^{3}$ International Max Planck Research School on Earth System Modelling, Hamburg, Germany \\ ${ }^{4}$ Hadley Centre, Met Office, Exeter, UK
}

Received: 25 August 2009 - Published in Atmos. Chem. Phys. Discuss.: 2 October 2009

Revised: 28 October 2010 - Accepted: 7 February 2011 - Published: 16 February 2011

\begin{abstract}
We present a method for deriving the radiative effects of absorbing aerosols in cloudy scenes from satellite retrievals only. We use data of 2005-2007 from various passive sensors aboard satellites of the "A-Train" constellation. The study area is restricted to the tropical- and subtropical Atlantic Ocean. To identify the dependence of the local planetary albedo in cloudy scenes on cloud liquid water path and aerosol optical depth (AOD), we perform a multiple linear regression. The OMI UV-Aerosolindex serves as an indicator for absorbing-aerosol presence. In our method, the aerosol influences the local planetary albedo through direct(scattering and absorption) and indirect (Twomey) aerosol effects. We find an increase of the local planetary albedo (LPA) with increasing AOD of mostly scattering aerosol and a decrease of the LPA with increasing AOD of mostly absorbing aerosol. These results allow us to derive the direct aerosol effect of absorbing aerosols in cloudy scenes, with the effect of cloudy-scene aerosol absorption in the tropical- and subtropical Atlantic contributing $(+21.2 \pm 11.1) \times 10^{-3} \mathrm{Wm}^{-2}$ to the global top of the atmosphere radiative forcing.
\end{abstract}

\section{Introduction}

The aim of this study is to investigate the radiative forcing at the top of the atmosphere (TOA) of absorbing aerosols in cloudy situations. We perform the analysis for the tropical and subtropical Atlantic Ocean region over a three-year period (2005-2007) by means of satellite retrievals from pas-

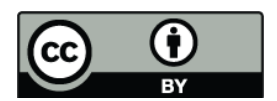

Correspondence to: K. Peters

(karsten.peters@zmaw.de) sive sensors only. The radiative effects of absorbing aerosols in cloudy skies have not yet been studied over such large spatial- and long timescales.

Aerosols lead to a number of radiative effects in the atmosphere and therefore influence the climate system. This study mainly focuses on aerosol direct radiative effects (DREs), namely the scattering and absorption of radiation by aerosol particles (Ångström, 1962; McCormick and Ludwig, 1967). Absorption of radiation by aerosols also exerts the so-called semi-direct effect, altering the average cloud fraction by locally heating cloud- and near-cloud air layers (Hansen et al., 1997; Johnson et al., 2004). Most recently, Wilcox (2010) has found evidence for the thickening of a cloud layer underlying a layer of absorbing aerosols. Aerosols also act as cloud condensation nuclei. Therefore, changes in aerosol concentration lead to changes in cloud microphysical properties, which then lead to a change in cloud albedo (e.g. Twomey, 1974; Lohmann and Feichter, 2005). It is debated whether a modification of cloud microphysical properties also leads to the so-called cloud-lifetime effect (Albrecht, 1989; Stevens and Feingold, 2009). A further investigation of aerosol radiative effects is needed, since the uncertainty associated with these leads to the largest uncertainties when quantifying climate sensitivity (Forster et al., 2007).

Absorbing aerosols are characterised by a wavelength dependent single scattering albedo $(\operatorname{SSA}(\lambda))$, i.e. the wavelength dependent ratio of scattering to total extinction, less than unity. For most atmospheric aerosol species, scattering dominates over absorption of radiation in the visible spectral range. The direct radiative forcing (DRF) at TOA exerted by a layer of aerosol depends on the albedo of the underlying surface and the aerosol $\operatorname{SSA}(\lambda)$. In cloud-free scenes, even strongly (but still also scattering) absorbing aerosols impose

Published by Copernicus Publications on behalf of the European Geosciences Union. 
a negative TOA DRF over ice-free oceanic regions due to the dark underlying surface - the local planetary albedo $\alpha$ is increased. If the albedo of the lower boundary of the atmospheric column increases, such as in the case of clouds residing below aerosols, absorbing aerosols can exert a positive TOA DRF (e.g. Haywood and Shine, 1997; Keil and Haywood, 2003). In this case, the absorption of the particles dominates the scattering for the net TOA effect $-\alpha$ is decreased.

Different approaches towards quantifying the TOA DRF of absorbing aerosols overlying high-reflective surfaces, such as clouds, have been made. The first approaches towards this quantification were made using radiative-transfer modelling of aerosol layers overlying a high-albedo surface. Indeed, it was found that the TOA DRF of the aerosol is positive and increases with the albedo of the surface (Haywood and Shine, 1997; Liao and Seinfeld, 1998a,b). It was also found, that a positive but lower TOA DRF occurs, when soot aerosol is externally mixed within a cloud layer (Haywood and Shine, 1997).

As more detailed measurements became available, a combination of measurements and radiative-transfer calculations was used to infer the TOA DRF of absorbing aerosols residing above clouds. Keil and Haywood (2003) used field measurements of the SAFARI 2000 campaign (Swap et al., 2002) to analyse the TOA DRF of biomass-burning aerosol overlying the stratocumulus decks off the coast of Namibia and Angola. They found that the presence of low clouds converted the originally negative TOA DRF of the aerosol layer in a cloud-free scene to a positive TOA DRF of the same magnitude (from $-13.0 \mathrm{Wm}^{-2}$ to $+11.5 \mathrm{Wm}^{-2}$ ). The same geographic region is the focus of a satellite data based study by Chand et al. (2009), who also employ a radiativetransfer model for deriving the TOA DRF. They used data spanning two biomass-burning seasons (July-October 2006 and 2007) and found that the sign of the TOA DRF exerted by absorbing aerosols above clouds depends on the cloud fraction. The cloud fraction, above which the TOA DRF of absorbing aerosols above clouds is positive, is found to be 0.4 . The mean of this TOA DRF is approximately identical to that of Keil and Haywood (2003).

Using satellite retrievals of 2006, Stammes et al. (2008) investigated cloudy scenes showing absorbing aerosol presence. An identification of these scenes is done on a global scale, but the corresponding TOA DRF is derived for the region of southwest Africa and the adjacent Atlantic Ocean only. A shortwave heating of the atmosphere in the range of 0 to $+80 \mathrm{Wm}^{-2}$, with a mean of $+35 \mathrm{Wm}^{-2}$, is derived by comparing reflectance spectra of clean and polluted scenes.

A method for quantifying aerosol-cloud overlap and the optical properties of the respective aerosol layer from passive remote sensing only was recently developed by Waquet et al. (2009). First, they found that different retrieval schemes for cloud top pressure yield significantly different results when an aerosol layer resides above clouds. This en- ables a quantification of aerosol-cloud overlap. Second, the fact that aerosols overlying a cloud significantly affect the polarised light reflected by the cloud allowed Waquet et al. (2009) to estimate the aerosol optical depth of the aerosol layer.

In our study, we use satellite data to quantify the radiative effect of absorbing aerosols in cloudy scenes over the subtropical and tropical Atlantic Ocean region for the years 2005-2007. We use measurements of passive-remotesensing instruments on satellites flying in the "A-Train" constellation (Stephens et al., 2002; Anderson et al., 2005). Our study is thus the first attempt to quantify the TOA DRF of absorbing aerosols in cloudy scenes on large spatial- and long timescales.

The data used in this study is presented in Sect. 2. The method and results of deriving a quantitative relationship of cloudy-scene broadband-shortwave $\alpha$ and AOD as well as an evaluation with reanalysis data are presented and discussed in Sect. 3. The Method and results of the radiative forcing calculations are shown and discussed in Sect. 4. Finally, we summarise the results and draw conclusions in Sect. 5.

\section{Data}

The A-Train satellite constellation currently consists of five satellites which orbit the Earth in formation (Stephens et al., 2002; Anderson et al., 2005). The time difference between the first satellite, EOS (Earth Observing System) Aqua, and the last satellite, EOS Aura, is eight minutes.

The main advantage of the A-Train is the possibility of combining all measured data due to the collocation in time and space. We combine measurements of cloud, aerosol and radiative properties to derive the TOA RF of absorbing aerosols in cloudy scenes. For this, we use data covering the Atlantic Ocean from $35^{\circ} \mathrm{N}$ to $30^{\circ} \mathrm{S}$ at a resolution of $0.25^{\circ} \times 0.25^{\circ}$ for the years $2005-2007$. We only use data acquired by instruments mounted on EOS-Aqua (Parkinson, 2003) and EOS-Aura (Schoeberl et al., 2006) and the products used in this study are introduced in the following.

\subsection{MODIS}

MODIS (MODerate resolution Imaging Spectrometer) on EOS Aqua measures the upwelling radiance in 36 channels within the spectral range from 0.44 to $15 \mu \mathrm{m}$, has a swath width of $2300 \mathrm{~km}$ and a spatial resolution ranging from 250$1000 \mathrm{~m}$. Measurements of MODIS can be used to derive aerosol- and cloud properties over land- and ocean regions (King et al., 1992; Kaufman et al., 1997; Tanré et al., 1997; Yu et al., 2006). We use these properties in this study and the datasets suiting this purpose are the MYD08_D3 and MYDATML2 collection 5 datasets.

Macrophysical cloud properties needed for this study are provided at high spatial resolution $\left(1 \times 1 \mathrm{~km}^{2}\right.$, sub-sampled to 
$5 \times 5 \mathrm{~km}^{2}$ ) in the MYDATML2 product. From this product, we use the retrieved cloud fraction and cloud top temperature (named "Cloud_Fraction" and "Cloud_Top_Temperature" in the data), which we average to a $0.25^{\circ} \times 0.25^{\circ}$ grid. We use daytime data granules only and perform a rigorous quality control on the retrieved cloud properties, using only pixels which are flagged as "cloudy" and retrieved as having "single layer liquid water cloud". We take the $\operatorname{AOD}(0.55 \mu \mathrm{m})$ from the MYD08_D3 daily Level3 product on a $1^{\circ} \times 1^{\circ}$ grid. Because we aim at analysing cloud-aerosol interactions at $0.25^{\circ} \times 0.25^{\circ}$, the AOD is applied at all 16 $0.25^{\circ} \times 0.25^{\circ}$ pixels within the larger $1^{\circ} \times 1^{\circ}$ pixel. This implies the AOD being homogeneously distributed over $1^{\circ} \times 1^{\circ}$, which is in line with the results by Anderson et al. (2003).

\subsection{AMSR-E}

AMSR-E (Advanced Microwave Scanning RadiometerEarth Observing System; Kawanishi et al., 2003) is installed on EOS Aqua and provides global passive microwave measurements. Horizontally and vertically polarised brightness temperatures are measured in six channels, from $6.9 \mathrm{GHz}$ to $89.0 \mathrm{GHz}$ and the spatial resolution varies from $5.4 \mathrm{~km}$ at $89 \mathrm{GHz}$ to $56 \mathrm{~km}$ at $6.9 \mathrm{GHz}$.

Important for this study is the derivation of the cloud liquid water path (LWP) from AMSR-E measurements at $36.5 \mathrm{GHz}$ (Wentz, 1997). We obtain the data from REMSS (REMote Sensing Systems, www.remss.com) and grid the data onto a $0.25^{\circ} \times 0.25^{\circ}$ grid. We only use scenes having a retrieved $\mathrm{LWP} \geq 20 \mathrm{~g} \mathrm{~m}^{-2}$, as this is a threshold approximately equivalent to a cloud optical depth $>4$, from which on cloud microphysical property retrievals can be considered reliable (Nakajima and King, 1990).

\subsection{CERES}

CERES (Clouds and the Earth's Radiant Energy System; Wielicki et al., 1996; Loeb and Manalo-Smith, 2005) is an instrument aboard EOS Aqua and measures the upwelling short- and longwave radiation at about $20 \times 20 \mathrm{~km}^{2}$ horizontal resolution. The measured radiances are converted into TOA fluxes as a function of viewing- and solar zenith angles by the use of Angular Distribution Models (ADMs) and allow for a detailed computation of the Earth's radiation budget. In this study, we use the CERES single-scanner-footprint (SSF) product. This is a Level2 product which combines MODIS and CERES measurements, with the MODIS measurements averaged to fit the footprint size of CERES.

In this study, we only use the spectrally averaged $(0.3-5 \mu \mathrm{m})$, upwelling shortwave radiative flux at TOA (CERES_SW_TOA_flux_-_upwards). We convert it to the local planetary albedo $\alpha$ by relating the outgoing shortwave flux to the incoming solar insolation. We compute the solar insolation by use of the CERES measured solar zenith angle at the surface, the eccentricity of Earth's orbit and a solar constant of $1365 \mathrm{Wm}^{-2}$ as used in the CERES retrievals. We grid the data, like the MODIS Level2 data, onto a $0.25^{\circ} \times 0.25^{\circ}$ global grid.

\subsection{OMI}

OMI (Ozone Monitoring Instrument; Levelt et al., 2006) is the follow-up of TOMS (Total Ozone Mapping Spectrometer; Heath et al., 1975) and is a spectrometer with high spectral resolution installed on EOS Aura. OMI has a swath width of $2600 \mathrm{~km}$ and offers nearly daily global coverage with a spatial resolution for the UV-2 and VIS (UV-1) channels ranging from $13 \times 24(48) \mathrm{km}^{2}$ to about $13 \times 150 \mathrm{~km}^{2}$. This resolution-range is due to pixel distortion at the outer edge of the swath.

The main advantage of OMI for this study is, that bulk aerosol radiative effects can be derived from its measurements in the UV spectral range also in cloudy scenes. We use the data from the OMAERUVG_V003 dataset, which is a gridded Level 2 dataset containing all retrievals from the OMAERUV (OMi near-UV; Torres et al., 2007) algorithm falling into a $0.25^{\circ} \times 0.25^{\circ}$ grid-box. This algorithm provides for a variety of aerosol radiative properties, such as $\operatorname{AOD}(0.388 \mu \mathrm{m})$, AOD of absorption, single scattering albedo for clear sky conditions and aerosol indices. Of these parameters, we only use the so-called UV-Aerosol Index (UV-AI) (Torres et al., 1998; de Graaf et al., 2005; De Vries et al., 2009). The properties of this index are important in the context of this study and we go into further detail on these in the next paragraph. For further processing, the mean of all measurements in each $0.25^{\circ} \times 0.25^{\circ}$ grid box is calculated.

\subsubsection{The UV-AI: a measure for aerosol absorption}

In this study, the UV-AI is the key parameter to identify absorbing aerosols. Therefore, we present a short review of the concepts and particularities of the UV-AI in this section. From these, we derive and provide constraints on the usability of the UV-AI in the scope of this study.

The UV-AI is a semi-quantative measure which allows for sampling of bulk radiative properties of aerosols in the UV. It is derived by relating the measured upwelling radiances at two wavelengths in the UV ( 354 and $388 \mathrm{~nm}$ for OMI; Torres et al., 2007) to those radiances obtained from a radiativetransfer model assuming molecular scattering only (Herman et al., 1997; Torres et al., 1998; de Graaf et al., 2005).

Radiative transfer calculations show that the UV-AI takes positive values for absorbing aerosol, negative values for non-absorbing aerosol and zero for clouds or purely molecular scattering (Herman et al., 1997; Torres et al., 1998; de Graaf et al., 2005). The same calculations show that the magnitude of the UV-AI explicitly depends on aerosol species, the height above the underlying surface (or cloud) as well as on the overall brightness of the observed scene. An advantage of the UV-AI is that it allows to detect the 
absorption due to the presence of the aerosol layer independently from the brightness of the overall scene in the visible spectral range. Thus it is possible to detect absorbing aerosols over and in clouds as well as over snow- or icecovered land surfaces (Torres et al., 2007).

We use the UV-AI for conditional sampling of the $0.25^{\circ} \times 0.25^{\circ}$ for further analysis. A threshold value of UV$\mathrm{AI}=0.7$ is used to distinguish between scenes mostly subject to aerosol absorption (UV-AI $\geq 0.7$ ) and scenes mostly subject to aerosol scattering (UV-AI $<0.7)$ (M. de Graaf, KNMI, pers. comm., 2008). Testing of this threshold shows, that this is the best fit between being able to sample for aerosol absorption and having enough data available for a robust statistical analysis.

\section{Statistical analysis of overcast scenes}

\subsection{Method}

The aim of this study is to analyse the radiative effects of absorbing aerosols in cloudy skies using satellite data measured by passive-remote-sensing instruments only. We focus on the subtropical- and tropical Atlantic Ocean, because this region is frequently influenced by absorbing aerosols. These aerosols are mainly injected into the atmosphere over land (e.g. desert-dust- or biomass-burning aerosol) and then advected over oceanic regions. The subtropical- and tropical Atlantic Oceanic air masses are heavily influenced by emissions from the Africa. Therefore, the areas in the northand southeast subtropical- and tropical Atlantic Ocean covered by stratocumulus decks can be considered as offering ideal conditions for observing absorbing aerosols in cloudy scenes (Keil and Haywood, 2003; Haywood et al., 2004; Stammes et al., 2008; Doherty et al., 2008; Chand et al., 2009; Costantino and Bréon, 2010; Wilcox, 2010).

We choose here not to use the active-remote-sensing instrument CALIOP (Cloud-Aerosol Lidar with Orthogonal Polarization; Kim et al., 2008). Analysis of a newly compiled CALIOP dataset (Devasthale and Thomas, 2010) has shown, that we can not use this data in the scope of our study, because of the sparse spatial coverage of the CALIOP instrument.

A three year (2005-2007) time frame spanning dataset over the tropical- and subtropical Atlantic Ocean is used to derive statistical relationships between the aerosol concentration and changes of the local planetary albedo $\alpha$ of an observed scene. Only oceanic regions are used, because measurements of the cloud liquid water path (LWP) from AMSR$\mathrm{E}$ are not available over land.

\subsubsection{Cloudy-scene absorbing-aerosol identification}

In this study, data from MODIS and OMI is used to check for aerosol absorption in cloudy scenes. We use cloud properties from the fine resolution MODIS product, $\operatorname{AOD}(0.55 \mu \mathrm{m})$

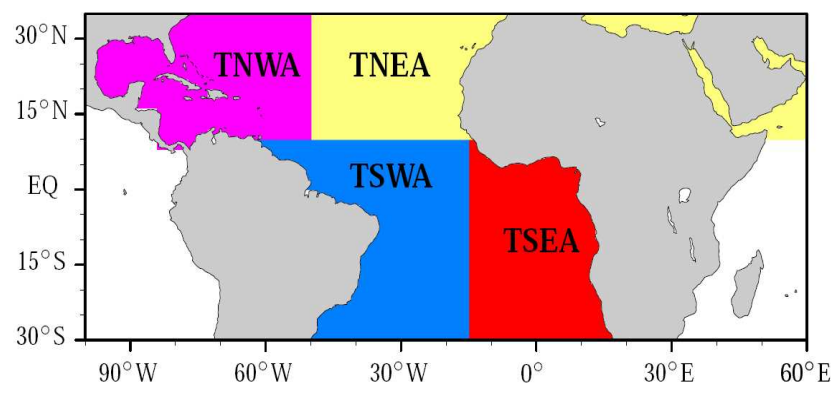

Fig. 1. Choice of different oceanic regions.

from the coarse resolution aggregated MODIS product and the UV-AI from OMI (see Sect. 2). We assume the AOD derived from MODIS measurements in the clear parts of a $1^{\circ} \times 1^{\circ}$ grid box as representative for the entire grid box (Anderson et al., 2003). Because we are interested in liquid water clouds, we select overcast scenes with a cloud top temperature greater than $273.15 \mathrm{~K}$. Overcast scenes must yield a cloud fraction of $100 \%$ at the $0.25^{\circ} \times 0.25^{\circ}$ resolution we average the fine-resolved MODIS Level 2 cloud fraction to (Sect. 2.1) and $\alpha$ obtained from CERES measurements must be greater than 0.1. Then, the AOD and the UV-AI for this scene are used to characterise the bulk radiative properties of the observed aerosol. A threshold value of UV-AI $=0.7$ is used to allow the separation of the overcast scenes into those mostly subject to aerosol absorption and those mostly subject to aerosol scattering.

We acknowledge, that aerosol absorption is a wavelengthdependent process depending on the aerosol type. While biomass burning aerosol yields high absorption throughout the broadband shortwave spectrum, dust mainly absorbs in the UV (Bergstrom et al., 2007). We do not explicitly account for wavelength-dependence of aerosol absorption, but aim at characterising the bulk radiative effect of an observed aerosol population.

\subsubsection{Geographical- and temporal distribution of absorbing aerosols}

We account for differences in the aerosol characteristics with respect to geographical location by dividing the tropical and subtropical Atlantic Ocean into four different regions. The classification of areas is displayed in Fig. 1 with the acronyms explained in Table 1.

Bulk aerosol characteristics in each region are assumed to be similar on seasonal timescales. We have tested this assumption using the analysis of anthropogenic- versus natural fractions of AOD as described in Bellouin et al. (2005), using MODIS collection 5 data from EOS-Aqua. The MODIS retrieved accumulation mode fraction (AMF, particles smaller than $1 \mu \mathrm{m}$ ) is used to discriminate between natural- and anthropogenic aerosols. Particles contained in the accumulation mode are treated as anthropogenic (e.g. biomass-burning 
aerosols) and others as natural particles (e.g. mineral-dust aerosols). If mixtures of biomass-burning- and mineral-dust aerosols are identified, the AMF of the retrieved AOD is treated as anthropogenic. We test our assumption of similar bulk-aerosol characteristics on seasonal timescales seasonwise for each region separately (see Table 1 for acronyms). The plots illustrating the results of this testing are given in Figs. S1-S4 of the Supplement to this paper. The analysis of aerosol distributions shows, that the region TSEA is the only one yielding a significant fraction of pollution by small-size absorbing-particles. The highest of those fractions is derived when the biomass-burning season (JJA, SON) in central to southern Africa occurs. During JJA, the region TSEA is also found to be polluted by larger-size absorbingparticles, which is due to the anthropogenic-AOD algorithm design described in Bellouin et al. (2005): biomass-burningaerosol populations may have a significant fraction of particles larger than $1 \mu \mathrm{m}$ (Remer et al., 1998). So by design, the algorithm described in Bellouin et al. (2005) defines this aerosol as natural, although it is of anthropogenic origin. The region TSWA is subject to similar pollutant fractions as region TSEA, most certainly owing to biomass-burningaerosol advection from the African continent. For the region TNWA, we find elevated levels of small-size absorbingparticles MAM. These probably stem from biomass burning in the Caribbean during the local dry season (Robbins et al., 2008).

The Region TNEA shows no significant pollution by small-size absorbing-particles. The bulk of observed absorbing particles is of natural origin, being in accordance with frequent dust outbreaks from the Sahara region. We find the same for the region TNWA, indicating the observation of long-range dust-transport (Doherty et al., 2008).

We conclude that in the regions TSEA and TSWA, aerosol absorption predominantly stems from biomass burning aerosol. In the region TNEA, aerosol absorption mostly stems from mineral dust aerosol. The same holds for the region TNWA, where a small contribution from biomass burning aerosol is observed in MAM. Due to this geographic- and temporal distribution of absorbing aerosol in the subtropical and tropical Atlantic Ocean, we are effectively able to separate the two types of spectral-absorption characteristics (mainly in the UV for dust, broadband for biomass-burning aerosol) by use of the four defined regions.

\subsubsection{The local-planetary-albedo linear-model}

We compute the relationship between observed $\alpha$, LWP and $\operatorname{AOD}(0.55 \mu \mathrm{m})$ by means of a multiple linear regression. $\alpha$ of a scene overcast with liquid water clouds depends on the surface- and cloud albedo as well as the AOD. We represent $\alpha$ in scenes overcast with liquid water clouds in terms of the natural logarithm of LWP and AOD by a multiple linear regression of the form

$\alpha=a_{0}+a_{1} \ln (\mathrm{LWP})+a_{2} \ln (\mathrm{AOD})$.
Table 1. Acronyms for the regions displayed in Fig. 1, and for the seasons.

\begin{tabular}{cc}
\hline TNWA & tropical northwest Atlantic \\
TNEA & tropical northeast Atlantic \\
TSWA & tropical southwest Atlantic \\
TSEA & tropical southeast Atlantic \\
\hline DJF & December, January, February \\
MAM & March, April, May \\
JJA & June, July, August \\
SON & September, October, November \\
\hline
\end{tabular}

$\alpha$ is derived from the CERES TOA shortwave flux, LWP is taken from AMSR-E and $\operatorname{AOD}(0.55 \mu \mathrm{m})$ is taken from the coarse resolution MODIS dataset. All three quantities $(\alpha$, LWP and AOD) are derived from independent coincident retrievals and overcast scenes are derived as described in Sect. 3.1.1.

We characterise the contribution of clouds to $\alpha$ by taking the influences of cloud macro- and microphysics into account separately. Macrophysical cloud properties are introduced by the LWP, as this quantity is mostly influenced by local meteorological conditions (Stevens and Feingold, 2009, and references therein). Microphysical cloud properties are mainly dependent on the ambient aerosol population. Therefore, microphysical properties are introduced into Eq. 1 by the AODdependency. By doing this, we include both direct- and indirect aerosol effects in the third right-hand-side term of Eq. 1. Cloud droplet number concentration, the relevant quantity for aerosol indirect effects, can be approximated as a function of AOD (Quaas et al., 2008; Andreae, 2009).

We are aware that retrievals of cloud optical depth and cloud droplet effective radius are available. But these can be strongly affected when performed in the presence of absorbing aerosols (Haywood et al., 2004; Wilcox et al., 2009). We use LWP retrievals in the microwave spectral-range, because these are less affected by aerosol-radiation interactions than retrievals in the visible spectral-range, thus yielding better results for cloud properties in absorbing aerosol contaminated scenes (Wilcox et al., 2009; Seethala and Horváth, 2010).

In the scope of our study, we concentrate on direct scattering/absorption of incident solar radiation by aerosols above or inside the cloud layer and the first indirect effect (Twomey effect). In situations where both effects take place, we sample a combination of direct- and indirect aerosol effects. We explicitly do not take further indirect- or semi-direct effects into account, because we hold the LWP and cloud fraction constant when performing the regression analysis. Nevertheless, it is recognised that semi-direct effects are present in at least on of the regions of interest (TSEA, as most recently elucidated by Wilcox, 2010).

We calculate the multiple regression coefficients $a_{0}, a_{1}$ and $a_{2}$ for the two UV-AI bins $(<0.7, \geq 0.7$; see Sect. 3.1.1) 
Table 2. Amount of measurements used for the regression analysis in Eq. (1).

\begin{tabular}{lccc}
\hline & & \multicolumn{2}{c}{ Fractional amount of measurements } \\
Region & Total $/ 10^{5}$ & UV-AI $<0.7$ & UV-AI $\geq 0.7$ \\
\hline TNWA & 0.23 & 0.84 & 0.16 \\
TNEA & 0.58 & 0.65 & 0.35 \\
TSWA & 0.63 & 0.77 & 0.23 \\
TSEA & 1.7 & 0.61 & 0.39 \\
\hline
\end{tabular}

for all four regions as follows: In order to get an error estimate, regressions are performed for slabs of 500 randomly picked measurement triplets ( $\alpha$, LWP and AOD) of each region. By application of this method, we take possible dependencies on intra-regional variations in background conditions into account. We define the regression slope error as the standard deviations of the about 10-200 slopes offered by this approach for each of the four regions. We acknowledge the fact that the measurements we are using are subject to a large number of uncertainties (Wentz, 1997; Loeb, 2004; Remer et al., 2005) and we assume all of these uncertainties being incorporated in the standard deviations obtained from the procedure explained above.

To get an impression of the performance of our model (Eq. 1), we correlate CERES-measured $\alpha$ vs. $\alpha$ obtained from our model using the measurements of AOD, LWP and UV-AI. The scatterplots can be obtained as Fig. S5-S6 in the Supplement to this paper. The scatterplots show an overall good agreement between measured and modelled LPA values. Nevertheless, the results scatter about the 1:1 line, which also reflects in the correlation coefficients ranging from about 0.6 to about 0.75 . We assume a large part of the scatter about the 1:1 line to reflect the uncertainties associated with the satellite data (Wentz, 1997; Loeb, 2004; Remer et al., 2005). These uncertainties are included in the error analysis via the uncertainty associated with the $a_{2}$ coefficient.

\subsection{Results}

The absolute- and fractional amount of measurements used for the regression analysis are displayed in Table 2. We find that the proportion of scenes with aerosol absorption identified in cloudy scenes varies significantly between the regions: $39 \%$ for the region TSEA vs. $16 \%$ for the region TNWA. The two regions bordering the western coast of Africa, TSEA and TNEA, both have a higher fraction of absorbing-aerosol observations than the neighbouring regions to the west. This is due to deposition of aerosol which is emitted over land and then advected over the ocean.

In the multiple regression, the coefficient $a_{2}$ quantifies the dependency of planetary albedo on AOD. The calculated values for the coefficients $a_{2}$, along with their respective standard deviations, are shown in Fig. 2.

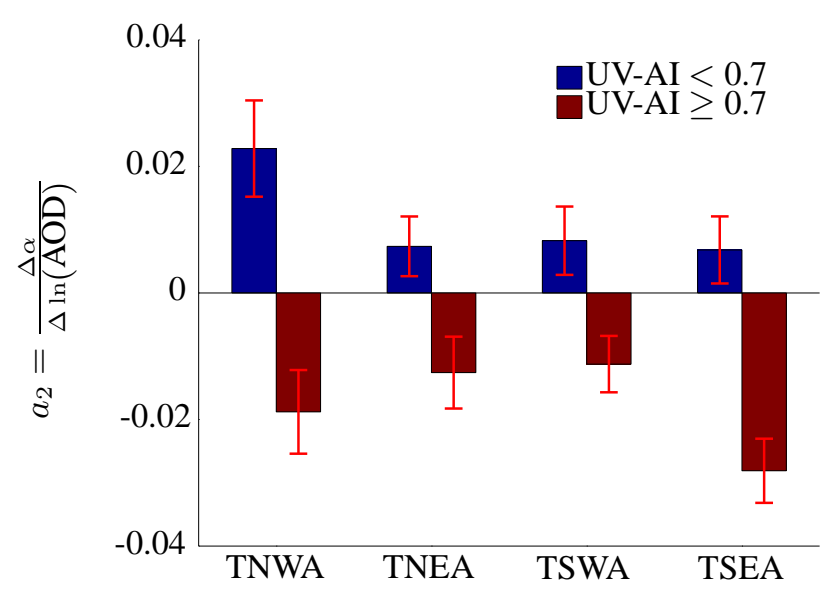

Fig. 2. Result from the regressions analysis: coefficients $a_{2}$ in Eq. (1) and respective standard deviations for the selected regions.

For an UV-AI $<0.7, \alpha$ is found to increase with AOD in all regions. This positive dependence of $\alpha$ on AOD for mostly scattering aerosols in cloudy scenes can be attributed to a combination of the (scattering) aerosol direct effect and the increase in cloud albedo by the aerosol indirect effect. Since we stratify by LWP in the multiple regression, only the Twomey effect (first indirect effect; Twomey, 1974) is considered here.

This increase in $\alpha$ for scenes with an UV-AI $<0.7$ is larger for the two northern regions (TNEA, TNWA) than for the two southern regions (TSEA, TSWA). This may be due to weakly-absorbing biomass-burning aerosol even in scenes yielding an UV-AI $<0.7$ in the two southern regions. This effect is not seen in the two northern regions, because mineral dust strongly absorbs radiation in the UV where the UV-AI is derived. Therefore, a separation between absorbing- and scattering aerosol is more feasible in regions subject to mineral dust pollution when mineral dust is the only absorbingaerosol species present (see Sect. 3.1.2).

For scenes with an UV-AI $>0.7$, negative coefficients $a_{2}$ are calculated for all considered regions. This is expected, because an increase in aerosol absorption in cloudy scenes leads to a reduction of $\alpha$ at TOA in particular if the aerosols are above the clouds. Although we do not sample for aerosols above clouds explicitly, the results suggest that absorbing aerosol above clouds is sampled and its TOA radiative effect is derived.

The largest reduction of $\alpha$ with AOD is derived for the region TSEA. This is expected, because this region is heavily influenced by advected biomass-burning aerosol from Africa (e.g. Keil and Haywood, 2003). Biomass-burning aerosol yields a strong broadband-shortwave absorption (Bergstrom et al., 2007), resulting in a large radiative effect in the broadband-shortwave spectral-region $(0.3-5 \mu \mathrm{m})$ for which $\alpha$ is defined. Accordingly, the results for the region TNEA, in which the predominant absorbing aerosol species is dust, 
show a much lesser reduction of $\alpha$ per unit AOD. This can be explained as follows: Dust aerosol has significantly different spectral-absorption characteristics than biomass burning aerosol. Because dust aerosol mainly absorbs in the UV spectral range, its radiative effect in the broadbandshortwave spectral-region for which $\alpha$ is defined is less pronounced than for biomass-burning aerosol. This is reflected in the less negative values of $a_{2}$ for the region TNEA.

For the region TNWA, we find a reduction of $\alpha$ per unit AOD which is just in between the values for the regions TSEA and TNEA. We know from the seasonal analysis (see Supplement Figs. S1-S4 and Sect. 3.1.2) that the region TNWA is influenced by long range dust transport as well as biomass-burning events. Therefore, we sample a mixture of both aerosol species which is reflected in the calculated value of $\mathrm{a}_{2}$.

The aerosol observed in the region TSWA leads to the least absorption in cloudy scenes.

\subsection{Validation with reanalysis data}

Because we do not sample for the vertical distribution of cloud- and aerosol layers in the linear model described in Sect. 3.1.3, we have applied the Global Earth system Monitoring using Satellite and in-situ data (GEMS)reanalysis product, where satellite data are assimilated into the ECMWF atmospheric model (Hollingsworth et al., 2008) for this purpose.

Reanalysis data from the GEMS project contains threedimensional distributions of a variety of aerosol species. These distributions are obtained by assimilation of measurement data, e.g. from satellites. Therefore, these data provide a valuable source of information for our analysis: the vertical position of clouds and aerosols in the atmospheric column.

By use of the GEMS-reanalysis data, we want to test, whether the UV-AI is suited for detecting layers of absorbing aerosol above clouds in the case of UV-AI $>0.7$. If this is the case, then the scenes with an UV-AI $<0.7$ should represent those cases, in which both direct- and indirect aerosol effects take place.

We use GEMS-reanalysis data at daily resolution (12:00 UTC output) for the whole time period of interest. As the equator crossing time of the A-Train satellite constellation is about 01:30 p.m., the 12:00 UTC model output represents the sampled situations best in the Atlantic region. The analysed parameters are the vertical distributions of cloud fraction, hydrophobic - and hydrophilic black carbon as well as dust $(0.55-0.9 \mu \mathrm{m}$ size range). GEMS further considers sulfate and sea salt aerosols but these species are not relevant in the scope of our study.

The aim of analysing the GEMS data is to obtain a clear separation between those scenes showing thick aerosol layers above clouds and those scenes in which this is not the case. Therefore, we use the vertical profiles of carbonaceous and dust aerosols from the GEMS reanalysis to identify ab-

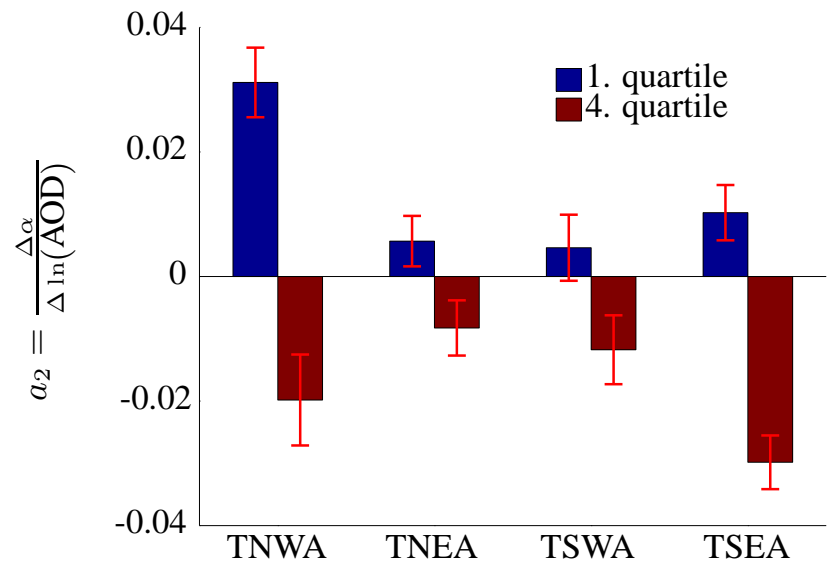

Fig. 3. Result from the regressions analysis using GEMS-reanalysis data instead of the UV-AI (Sect. 3.3): coefficients $a_{2}$ in Eq. (1) and respective standard deviations for the selected regions.

sorbing aerosol layers. The peak in the profiles of these species is considered a layer if it is in the upper quartile of the carbonaceous- and dust aerosol distributions, and if it is located above a cloud layer as diagnosed by the reanalysis. The lower quartile is taken as control value.

We then use the information contained in the quartiles to substitute the UV-AI measurements. For this, we apply the GEMS-data as a mask for our satellite data (MODIS, CERES and AMSR-E) which is similar to the application of the UVAI: if GEMS-data suggest an aerosol profile with characteristics corresponding to the lower quartile (see above), we assume that certainly no absorbing aerosol layer above a cloud layer is present, and otherwise, if GEMS-data suggest an aerosol profile with characteristics corresponding to the upper quartile, we identify an absorbing aerosol layer above the cloud. Then, the regression analysis is performed as described in Sect. 3.1.3 similar to the cases UV-AI $<0.7$ (lower aerosol quartile) and UV-AI $>0.7$ (upper quartile). The results for the coefficient $\mathrm{a}_{2}$ are shown in Fig. 3.

The results shown in Fig. 3 indeed closely reproduce those presented in our manuscript when using the UV-AI to identify absorbing aerosol. This suggests that the sampling of layers of absorbing aerosols by use of the UV-AI is a valid approach. Furthermore, these results support our assumption of sampling scenes dominated by indirect aerosol effects for UV-AI $<0.7$, where an increase in LPA is to be expected.

It may also be the case, that absorbing aerosol is mixed within the cloud layer. This is important to consider, as this would also lead to a reduction of the LPA, as shown by Haywood and Shine (1997) who calculated the radiative effect of externally mixed soot in a cloud layer. We analysed the GEMS-data with respect to conditions in which the peak of the aerosol profile is located in a range close under- and above the peak of the cloud layer: this does practically not occur in the GEMS-data. Therefore, we do not have to take this effect into account explicitly. 


\section{Radiative forcing calculations}

\subsection{Method}

We compute the contribution of the effect of anthropogenic aerosols in cloudy scenes to the all-sky top-of-theatmosphere (TOA) radiative forcing (RF) as

$F_{\text {ant }}^{\text {cld }}=\bar{F} \Delta \alpha_{\text {ant }} \mathrm{LCF}$,

with $\bar{F}$ the incoming daily mean TOA solar radiation, LCF the liquid water cloud fraction and $\Delta \alpha_{\text {ant }}$ the change in local planetary albedo $\alpha$ defined as

$\Delta \alpha_{\text {ant }}=\alpha_{\text {tot }}-\alpha_{\text {nat }}$,

with

$\alpha_{\text {nat }}=a_{0}+a_{1} \ln (\mathrm{LWP})+a_{2} \ln \left(\mathrm{AOD}_{\text {tot }}-\mathrm{AOD}_{\mathrm{ant}}\right)$,

and

$\alpha_{\text {tot }}=a_{0}+a_{1} \ln (\mathrm{LWP})+a_{2} \ln \left(\mathrm{AOD}_{\text {tot }}\right)$,

where $\mathrm{AOD}_{\text {tot }}$ is the total $\mathrm{AOD}$ and $\mathrm{AOD}_{\text {ant }}$ the anthropogenic AOD as described in Bellouin et al. (2005), derived with MODIS collection 5 data (as in Bellouin et al., 2008). To compute the forcing, we do not limit the used data to overcast scenes (as done before to compute the expression for the planetary albedo), but also use scenes with LCF $<1$ (see Eq. 2). By this approach, the forcing in all scenes involving liquid water clouds is taken into account, while the forcing in scenes with ice clouds or no clouds is not considered here (set to zero by the factor LCF in Eq. 2).

Firstly, the RF by all anthropogenic aerosols in scenes with liquid water clouds $F_{\text {ant }}^{\text {cld }}$ is computed choosing the regression applicable according to the retrieved UV-AI (larger or less than 0.7). Secondly, we separate the absorption effect to calculate an absorption forcing $F_{\text {ant abseff }}^{\text {cld }}$ by aerosol with an UV-AI $>0.7$ which is identified as anthropogenic by the algorithm of Bellouin et al. (2005) ("anthropogenic absorbing aerosol"). We use a coefficient $a_{2_{\text {eff }}}$ defined as

$a_{2_{\mathrm{eff}}}=\left.a_{2}\right|_{\geq 0.7}-\left.a_{2}\right|_{<0.7}$,

with $\left.a_{2}\right|_{<0.7}$ and $\left.a_{2}\right|_{\geq 0.7}$ being the calculated coefficients for scenes with an UV-AI $<0.7$ and $\geq 0.7$, respectively. Only scenes polluted by anthropogenic absorbing aerosol, defined by an UV-AI $\geq 0.7$, are used for the second setup. The absorption forcing $F_{\text {ant abseff }}^{\text {cld }}$ is considered zero in all other scenes. A detailed error analysis is performed for deriving the uncertainty related to the radiative forcing values. We include the uncertainties associated with the coefficients $\mathrm{a}_{0}, \mathrm{a}_{1}$ and $\mathrm{a}_{2}$ as well as the uncertainty of $5 \%$ given for the MODIS retrieved AOD over ocean (Remer et al., 2005). The uncertainties associated with CERES and AMSR-E measurements cancel out in Eq. (2). We assume a negligible uncertainty for LCF and $\bar{F}$ and therefore do not include these parameters in the error estimation.
Table 3. Annual mean global anthropogenic aerosol RF at TOA in cloudy scenes in $\mathrm{Wm}^{-2} .<F_{\text {ant }}^{\mathrm{cld}}>$ and $<F_{\text {ant abseff }}^{\text {cld }}>$ are the results obtained from the reference- and the absorption-effect calculation, respectively. Results are displayed for the whole subtropical- and tropical Atlantic (All regions) as well as for each region separately.

\begin{tabular}{ccc}
\hline Region & $<F_{\text {ant }}^{\text {cld }}>\times 10^{-3}$ & $<F_{\text {ant abseff }}^{\text {cld }}>\times 10^{-3}$ \\
\hline All regions & $+12.9 \pm 5.3$ & $+21.2 \pm 11.1$ \\
TNWA & $-0.79 \pm 1.02$ & $+0.28 \pm 0.36$ \\
TNEA & $-0.02 \pm 0.4$ & $+0.72 \pm 1.3$ \\
TSWA & $-0.28 \pm 0.94$ & $+0.72 \pm 0.77$ \\
TSEA & $+14 \pm 2.9$ & $+19.5 \pm 8.7$ \\
\hline
\end{tabular}

\subsection{Results}

The two RFs $F_{\text {ant }}^{\text {cld }}$ and $F_{\text {ant abseff }}^{\text {cld }}$ are calculated for each of the regions and seasons described in Table 1. A distinction between seasons is made to identify changing aerosol loadings in the course of one year, e.g. during the biomass-burning season in southern Africa.

We summarise the global yearly averaged total- and absorbing-aerosol RF by anthropogenic aerosols for each region in Table 3.

The regions TNWA, TNEA and TSWA, show negative $<F_{\text {ant }}^{\text {cld }}>$. There, aerosol scattering and the aerosol indirect effect are larger than aerosol absorption in cloudy scenes. As shown in Table 2, this is expected, because the majority of the identified scenes yields an UV-AI $<0.7$ in these three regions. For the region TSEA, $<F_{\text {ant }}^{\text {cld }}>$ is positive and much larger than the negative forcing of the other three regions. In fact, $<F_{\text {ant }}^{\text {cld }}>$ of the whole subtropical- and tropical Atlantic Ocean is dominated by the contribution of the region TSEA. The sign and magnitude of the forcing in region TSEA also follow directly from the results shown in Table 2 and Sect. 3.2. This is due to multiple factors: (1) The average cloud fraction and (2) the average anthropogenic AOD are much larger for the region TSEA than for the other regions, (3) high values of anthropogenic AOD often coincide with scenes yielding an UV-AI $>0.7$ and (4) the magnitude of $\left.\mathrm{a}_{2}\right|_{\geq 0.7}$ for the region TSEA is the largest among all calculated values of $a_{2}$. As a result, the distribution of calculated albedo changes for the region TSEA is skewed towards large reductions. For the other three regions, this distribution is skewed towards lower reductions.

The same considerations hold for the calculation of $\left\langle F_{\text {ant abseff }}^{\text {cld }}\right\rangle$. All regions show a TOA positive RF due to the absorption effect of absorbing aerosol in cloudy scenes, and the forcing of the whole subtropical- and tropical Atlantic Ocean is again dominated by the contribution of the region TSEA.

Because previous studies focussing on the radiative effects of absorbing aerosols above clouds have investigated 
Table 4. Anthropogenic aerosol RF at TOA in cloudy scenes in $\mathrm{Wm}^{-2}$ for region TSEA (see Fig. 1). Results are displayed for different seasons (see Table 1), averaged on global and local scale. $F_{\text {ant }}^{\mathrm{cld}}$ and $F_{\text {ant abseff }}^{\mathrm{cld}}$ are the results obtained from the reference and the absorption effect calculation, respectively.

\begin{tabular}{ccccc}
\hline & \multicolumn{2}{c}{$F_{\text {ant }}^{\text {cld }} \times 10^{-3}$} & \multicolumn{2}{c}{$F_{\text {ant abseff }}^{\text {cld }} \times 10^{-3}$} \\
Season & global & local & global & local \\
\hline MAM & $+2.56 \pm 0.98$ & $+111 \pm 41.6$ & $+4.08 \pm 2.26$ & $+177 \pm 98.7$ \\
JJA & $+27.4 \pm 3.26$ & $+1180 \pm 141$ & $+36.1 \pm 16$ & $+1555 \pm 688$ \\
SON & $+23.2 \pm 6.25$ & $+1003 \pm 267$ & $+33.9 \pm 14.6$ & $+1464 \pm 635$ \\
DJF & $+1 \pm 1.2$ & $+43 \pm 51.5$ & $+2.56 \pm 2$ & $+110 \pm 88.8$ \\
\hline
\end{tabular}

the region off the southern coast of Africa, we display the results of region TSEA in more detail in Table 4.

It is evident, that the TOA RF of absorbing aerosols in cloudy scenes in the region TSEA is subject to a pronounced seasonal cycle, with the maximum occurring during the time of June-November. The TOA RF of region TSEA can reach up to $+0.03 \pm 0.003 \mathrm{Wm}^{-2}$ as contribution to the globalmean forcing. The estimates of the direct aerosol effect presented in Forster et al. (2007) range from $-0.9 \mathrm{Wm}^{-2}$ to $-0.1 \mathrm{Wm}^{-2}$, with a best estimate of $-0.5 \mathrm{Wm}^{-2}$. Therefore, $\left.<F_{\text {ant }}^{\text {cld }}\right\rangle$ of region TSEA, which covers about $2.7 \%$ of the global area, amounts to about $6 \%$ of this best estimate, but is of different sign. The contribution of the region TSEA to the best estimate of Forster et al. (2007) is even larger when the absorption forcing $F_{\text {ant abseff }}^{\text {cld }}$ is considered $(\approx 7 \%)$.

Locally at individual grid-points, $F_{\text {ant }}^{\text {cld }}$ can reach a seasonal mean value of more than $+30 \mathrm{Wm}^{-2}$ near the coast of Angola (not shown), with a regional mean value of $+1.55 \pm$ $0.005 \mathrm{Wm}^{-2}$ and $+1.46 \pm 0.004 \mathrm{Wm}^{-2}$ in season JJA and SON, respectively (Table 4). Those numbers are even higher for the absorption forcing $F_{\text {ant abseff }}^{\text {cld }}$.

The months June-November correspond to the biomassburning season in southern Africa, giving rise to large scale elevated aerosol layers above the semipermanent stratocumulus-decks off the coast (Keil and Haywood, 2003). Therefore, the magnitude of TOA direct RF of those aerosol layers is subject to a pronounced seasonal cycle. The results we find in this study show the same systematic as previous studies for the TSEA region (Keil and Haywood, 2003; Schulz et al., 2006; Stammes et al., 2008; Chand et al., 2009), namely a significant positive TOA DRF when layers of absorbing aerosol reside above cloud layers. This, together with our evaluation using GEMS-reanalysis data (Sect. 3.3), gives confidence in the method applied in this study. It is therefore indeed possible to quantify the TOA DRF of absorbing aerosol layers above clouds by use of passive remote sensing only.

It should be emphasised that the RF values presented here are the contribution of the direct and first indirect aerosol effects in cloudy skies. The direct effect in clear skies as well as semi-direct- and second indirect effects would need to be taken into account for an estimate of the overall anthropogenic-aerosol RF in the region of interest.

Furthermore, due to stringent filtering of the satellite data, we did not take scenes with overlying cirrus into account. Because cirrus clouds can be permeable to shortwave radiation, the radiative effect of absorbing aerosol overlying the low cloud layer may occasionally be just as large in cirruscontaminated- as in cirrus-free scenes. Therefore, the RF values presented here may be underestimated.

\section{Summary and conclusions}

In this study, we aimed at investigating the direct radiativeforcing of absorbing aerosols in cloudy skies by means of passive-remote-sensing measurements from spaceborne instruments. We used a three-year spanning (2005-2007) dataset covering the tropical- and subtropical Atlantic Ocean with data from different satellite sensors in the "A-Train" constellation (Stephens et al., 2002; Anderson et al., 2005). With this, we performed a statistical analysis to find a relationship between local planetary albedo $\alpha$ and absorbingaerosol presence in cloudy scenes.

By the method presented in this paper, a multiple linear regression is performed to derive a statistical expression linking $\alpha$ derived from CERES to cloud liquid water path (LWP) from AMSR-E and aerosol optical depth (AOD) from MODIS in presence of low-level liquid water clouds as detected by MODIS. We use the UV-Aerosol Index (UV-AI) derived from OMI data as an indicator for absorbing-aerosol presence in cloudy scenes. For situations with scattering and only slightly absorbing aerosols (UV-AI <0.7), $\alpha$ increases with AOD, which is consistent with aerosol scattering and/or an aerosol indirect effect. In scenes with absorbing aerosols (UV-AI >0.7), in all regions, $\alpha$ decreases with AOD, hinting at the effect of aerosol absorption in the cloudy scenes. It must be stated, that this approach implies assumptions which play an important role for quantifying the radiative forcing of aerosols in cloudy scenes: we neither sample for the vertical structure of the atmospheric column, nor do we explicitly sample for aerosol absorption, i.e. AOD of absorption. Nevertheless, these results are supported by a validation 
exercise in which we used GEMS-reanalysis data to sample for aerosol layers overlying clouds. These results even suggest, that scenes showing an UV-AI $>0.7$ may very well represent cloud absorbing-aerosol overlap.

These relationships between $\alpha$ and AOD enabled us to estimate the large-scale long-term TOA RF of anthropogenic aerosols in cloudy scenes. The anthropogenic aerosol fraction is derived as described in Bellouin et al. (2005). The overall forcing is negative in three out of four regions and significantly positive in the region off the coast of Namibia and Angola (region TSEA). Due to the frequent presence of lowlevel clouds and the strong $\alpha$-AOD relationship, this region dominates the anthropogenic forcing in scenes with low-level clouds in the entire region investigated here. The RF of the entire region amounts to a contribution to the global annual mean anthropogenic aerosol forcing of $+0.014 \pm 0.006$ $\mathrm{Wm}^{-2}$. The global contribution of only aerosol absorption in cloudy scenes by anthropogenic aerosols is estimated at $+0.02 \pm 0.003 \mathrm{Wm}^{-2}$.

We performed a validation exercise with GEMS-reanalysis data (Hollingsworth et al., 2008) to check whether we are able to quantify the TOA RF of a layer of absorbing aerosol overlying a cloud layer. The results of this validation suggest, that we are indeed able to do so. This makes our study comparable to previous studies on this matter (Keil and Haywood, 2003; Stammes et al., 2008; Chand et al., 2009). Most of these earlier studies used either model calculations with prescribed vertical positions of aerosol and clouds, active remote-sensing instruments or both. Although we emphasise that we do not sample for the vertical position of cloud- and aerosol layers, the results show that we have indeed quantified the reduction of $\alpha$ resulting from absorbing aerosol overlying a cloud layer. In fact, our derived TOA RF agrees well with the previous studies, especially for the region off the coast of Southern Africa. A combination of passive-remotesensing data from satellite instruments is thus suited for investigating this effect on climate.

\section{Supplement related to this article is available online at: http://www.atmos-chem-phys.net/11/1393/2011/ acp-11-1393-2011-supplement.pdf.}

Acknowledgements. We thank the two anonymous reviewers who put a lot of effort into the revision process and their comments helped us to improve the paper significantly. Thanks to a lot to all the colleagues giving helpful advice throughout the conduction of this study, with special thanks to Hartmut Grassl, Oliver Krüger, Ákos Horváth, Stefan Kinne and Martin de Graaf. Many thanks to Dallas Murphy and Jochem Marotzke for giving a workshop on scientific writing at the MPI-M in Hamburg. Application of the input received there helped us to improve the clarity of the paper. CERES SSF data were obtained from the NASA Langley Research Center Atmospheric Sciences Data Center. MODIS data used in this study were acquired as part of NASAs Earth Science Enterprise. The MODIS Science Teams developed the algorithms for the AOD retrievals. The data were processed by the MODIS Adaptive Processing System and the Goddard Distributed Active Archive (DAAC). The Dutch-Finnish built OMI instrument is part of the NASA EOS Aura satellite payload. The OMI project is managed by NIVR and KNMI in Netherlands. The OMI data were also obtained from the DAAC. AMSR-E data are produced by Remote Sensing Systems and sponsored by the NASA Earth Science REASoN DISCOVER Project and the AMSR-E Science Team. Data are available at www.remss.com. This work was partly funded by the European Union FP6 Integrated Project QUANTIFY and by the European Commission under the EU Seventh Research Framework Programme (grant agreement No. 218793, MACC).

The service charges for this open access publication have been covered by the Max Planck Society.

Edited by: T. Garrett

\section{References}

Albrecht, B. A.: Aerosols, Cloud Microphysics, and Fractional Cloudiness, Science, 245, 1227-1230, 1989.

Anderson, T. L., Charlson, R. J., Winker, D. M., Ogren, J. A., and Holmen, K.: Mesoscale variations of tropospheric aerosols, J. Atmos. Sci., 60, 119-136, 2003.

Anderson, T. L., Charlson, R. J., Bellouin, N., Boucher, O., Chin, M., Christopher, S. A., Haywood, J., Kaufman, Y. J., Kinne, S., Ogren, J. A., Remer, L. A., Takemura, T., Tanré, D., Torres, O., Trepte, C. R., Wielicki, B. A., Winker, D. M., and Yu, H. B.: An "A-Train" strategy for quantifying direct climate forcing by anthropogenic aerosols, B. Am. Meteorol. Soc., 86, 1795-1809, doi:10.1175/BAMS-86-12-1795, 2005.

Andreae, M. O.: Correlation between cloud condensation nuclei concentration and aerosol optical thickness in remote and polluted regions, Atmos. Chem. Phys., 9, 543-556, 2009, http://www.atmos-chem-phys.net/9/543/2009/.

Ångström, A.: Atmospheric turbidity, global illumination and planetary albedo of the earth, Tellus, 14, 435-450, 1962.

Bellouin, N., Boucher, O., Haywood, J., and Reddy, M. S.: Global estimate of aerosol direct radiative forcing from satellite measurements, Nature, 438, 1138-1141, 2005.

Bellouin, N., Jones, A., Haywood, J., and Christopher, S. A.: Updated estimate of aerosol direct radiative forcing from satellite observations and comparison against the Hadley Centre climate model, J. Geophys. Res.-Atmos., 113, D10205, doi:10.1029/ 2007JD009385, 2008.

Bergstrom, R. W., Pilewskie, P., Russel, P. B., Redemann, J., Bond, T. C., Quinn, P. K., and Sierau, B.: Spectral absorption properties of atmospheric aerosols, Atmos. Chem. Phys., 7, 5937-5943, doi:10.5194/acp-7-5937-2007, 2007.

Chand, D., Wood, R., Anderson, T. L., Satheesh, S. K., and Charlson, R. J.: Satellite-derived direct radiative effect of aerosols dependent on cloud cover, Nat. Geosci., 2, 181-184, doi:10.1038/ NGEO437, 2009.

Costantino, L. and Bréon, F.: Analysis of aerosol-cloud interaction from multi-sensor satellite observations, Geophys. Res. Lett., 37, L11801, doi:10.1029/2009GL041828, 2010.

de Graaf, M., Stammes, P., Torres, O., and Koelemeijer, R.: Absorbing Aerosol Index: Sensitivity analysis, application to GOME 
and comparison with TOMS, J. Geophys. Res.-Atmos., 110, D01201, doi:10.1029/2004JD005178, 2005.

De Vries, M., Beirle, S., and Wagner, T.: UV aerosol indices from SCIAMACHY: introducing the SCattering Index (SCI), Atmos. Chem. Phys, 9, 9555-9567, doi:10.5194/acp-9-9555-2009, 2009.

Devasthale, A. and Thomas, M. A.: A global survey of aerosolliquid water cloud overlap based on four years of CALIPSOCALIOP data, Atmos. Chem. Phys.-Discuss., 10, 22109-22130, doi:10.5194/acpd-10-22109-2010, 2010.

Doherty, O. M., Riemer, N., and Hameed, S.: Saharan mineral dust transport into the Caribbean: Observed atmospheric controls and trends, J. Geophys. Res.-Atmos., 113, D07211, doi: 10.1029/2007JD009171, 2008.

Forster, P., Ramaswamy, V., Artaxo, P., Berntsen, T., Betts, R., Fahey, D. W., Haywood, J., Lean, J., Lowe, D. C., Myhre, G., Nganga, J., Prinn, R., Raga, G., Schulz, M., and Van Dorland, R.: Changes in Atmospheric Constituents and in Radiative Forcing, in: Climate Change 2007: The Physical Science Basis. Contribution of Working Group I to the Fourth Assessment Report of the Intergovernmental Panel on Climate Change, edited by Solomon, S., Qin, D., Manning, M., Chen, Z., Marquis, M., Averyt, K. B., Tignor, M., and Miller, H. L., Cambridge University Press, Cambridge, UK and New York, NY, USA, 2007.

Hansen, J., Sato, M., and Ruedy, R.: Radiative forcing and climate response, J. Geophys. Res.-Atmos., 102, 6831-6864, 1997.

Haywood, J., Osborne, S. R., and Abel, S. J.: The effect of overlying aerosol layers on remote sensing retrievals of cloud effective radius and cloud optical depth, Q. J. Roy. Meter. Soc., 130, 779800,2004

Haywood, J. M. and Shine, K. P.: Multi-spectral calculations of the direct radiative forcing of tropospheric sulphate and soot aerosols using a column model, Q. J. Roy. Meter. Soc., 123, 1907-1930, 1997.

Heath, D., Krueger, A., Roeder, H., and Henderson, B.: Solar backscatter and Ultraviolet and Total Ozone Mapping Spectrometer (SBUV-TOMS) for Nimbus G, Opt. Eng., 14, 323-331, 1975.

Herman, J., Bhartia, P., Torres, O., Hsu, C., Seftor, C., and Celarier, E.: Global distribution of UV-absorbing aerosols from Nimbus 7/TOMS data, J. Gephys. Res.-Atmos., 102, 16911-16922, 1997.

Hollingsworth, A., Engelen, R., Textor, C., Benedetti, A., Boucher, O., Chevallier, F., Dethof, A., Elbern, H., Eskes, H., Flemming, J., et al.: Toward a monitoring and forecasting system for atmospheric composition, Bull. Am. Meteorol. Soc, 89, 1147-1164, 2008.

Johnson, B., Shine, K., and Forster, P.: The semi-direct aerosol effect: Impact of absorbing aerosols on marine stratocumulus, Q. J. Roy. Meter. Soc., 130, 1407-1422, doi:10.1256/qj.03.61, 2004.

Kaufman, Y. J., Tanré, D., Remer, L. A., Vermote, E. F., Chu, A., and Holben, B. N.: Operational remote sensing of tropospheric aerosol over land from EOS moderate resolution imaging spectroradiometer, J. Geophys. Res.-Atmos., 102, 17051-17067, 1997.

Kawanishi, T., Sezai, T., Ito, Y., Imaoka, K., Takeshima, T., Ishido, Y., Shibata, A., Miura, M., Inahata, H., and Spencer, R.: The Advanced Microwave Scanning Radiometer for the Earth Observing System (AMSR-E), NASDA's contribution to the EOS for global energy and water cycle studies, IEEE T. Geosci. Remote, 41, 184-194, doi:10.1109/TGRS.2002.808331, 2003.

Keil, A. and Haywood, J.: Solar radiative forcing by biomass burning aerosol particles during SAFARI 2000: A case study based on measured aerosol and cloud properties, J. Geophys. Res.Atmos., 108, 8467, doi:10.1029/2002JHD002315, 2003.

Kim, S.-W., Berthier, S., Raut, J.-C., Chazette, P., Dulac, F., and Yoon, S.-C.: Validation of aerosol and cloud layer structures from the space-borne lidar CALIOP using a ground-based lidar in Seoul, Korea, Atmos. Chem. Phys., 8, 3705-3720, doi:10.5194/acp-8-3705-2008, 2008.

King, M. D., Kaufman, Y. J., Menzel, W. P., and Tanré, D.: Remote sensing of cloud, aerosol, and water vapor properties from the Moderate Resolution Imaging Spectrometer (MODIS), IEEE T. Geosci. Remote, 30, 2-27, 1992.

Levelt, P., van den Oord, G., Dobber, M., Malkki, A., Visser, H., de Vries, J., Stammes, P., Lundell, J., and Saari, H.: The ozone monitoring instrument, IEEE T. Geosci. Remote, 44, 1093-1101, doi:10.1109/TGRS.2006.872333, 2006.

Liao, H. and Seinfeld, J.: Effect of clouds on direct aerosol radiative forcing of climate, J. Geophys. Res.-Atmos., 103, 3781-3788, 1998 a.

Liao, H. and Seinfeld, J. H.: Radiative forcing by mineral dust aerosols: sensitivity to key variables, J. Geophys. Res.-Atmos., 103, 31637-31645, 1998b.

Loeb, N.: Angular models: Instantaneous and ensemble accuracy, in: 1st CERES-II Science Team Meeting Proceedings, NCAR, Boulder, Colorado, USA, 2004

Loeb, N. G. and Manalo-Smith, N.: Top-of-atmosphere direct radiative effect of aerosols over global oceans from merged CERES and MODIS observations, J. Climate, 18, 3506-3526, 2005.

Lohmann, U. and Feichter, J.: Global indirect aerosol effects: a review, Atmos. Chem. Phys., 5, 715-737, 2005.

McCormick, R. A. and Ludwig, J. H.: Climate Modification by Atmospheric Aerosols, Science, 156, 1358-1359, 1967.

Nakajima, T. and King, M.: Determination of the Optical-Thickness and Effective Particle Radius of Clouds from Reflected SolarRadiation Measurements .1. Theory, J. Atmos. Sci., 47, 18781893, 1990.

Parkinson, C.: Aqua: An Earth-observing satellite mission to examine water and other climate variables, IEEE T. Geosci. Remote, 41, 173-183, 2003.

Quaas, J., Boucher, O., Bellouin, N., and Kinne, S.: Satellite-based estimate of the direct and indirect aerosol climate forcing, J. Geophys. Res.-Atmos., 113, D05204, doi:10.1029/2007JD008962, 2008.

Remer, L., Kaufman, Y., Holben, B., Thompson, A., and McNamara, D.: Biomass burning aerosol size distribution and modeled optical properties, J. Geophys. Res.-Atmos., 103, 31879-31891, 1998.

Remer, L., Kaufman, Y., Tanre, D., Mattoo, S., Chu, D., Martins, J., Li, R., Ichoku, C., Levy, R., Kleidman, R., Eck, T., Vermote, E., and Holben, B.: The MODIS aerosol algorithm, products, and validation, J. Atmos. Sci., 62, 947-973, 2005.

Robbins, A. M. J., Eckelmann, C.-M., and Quinones, M.: Forest Fires in the Insular Caribbean, Ambio, 37, 528-534, 2008.

Schoeberl, M., Douglass, A., Hilsenrath, E., Bhartia, P., Beer, R., Waters, J., Gunson, M., Froidevaux, L., Gille, J., Barnett, J., et al.: Overview of the EOS Aura mission, IEEE Trans. Geosci. 
Remote Sens., 44, 1066-1074, 2006.

Schulz, M., Textor, C., Kinne, S., Balkanski, Y., Bauer, S., Berntsen, T., Berglen, T., Boucher, O., Dentener, F., Guibert, S., Isaksen, I. S. A., Iversen, T., Koch, D., Kirkevag, A., Liu, X., Montanaro, V., Myhre, G., Penner, J. E., Pitari, G., Reddy, S., Seland, O., Stier, P., and Takemura, T.: Radiative forcing by aerosols as derived from the AeroCom present-day and preindustrial simulations, Atmos. Chem. Phys., 6, 5225-5246, doi: 10.5194/acp-6-5225-2006, 2006.

Seethala, C. and Horváth, Á.: Global assessment of AMSR$\mathrm{E}$ and MODIS cloud liquid water path retrievals in warm oceanic clouds, J. Geophys. Res., 115, D13202, doi:10.1029/ 2009JD012662, 2010.

Stammes, P., Tilstra, L. G., Braak, R., de Graaf, M., and Aben, E. A. A.: Estimate of Solar Radiative Forcing by Polluted Clouds Using OMI and SCIAMACHY Satellite Data, in: CURRENT PROBLEMS IN ATMOSPHERIC RADIATION (IRS 2008): Proceedings of the International Radiation Symposium (IRC/IAMAS), edited by Nakajima, T. and Yamasoe, M. A., Foz do Iguacu, Brazil, 3-8 August 2008, 577-580, 2008.

Stephens, G. L., Vane, D. G., Boain, R. J., Mace, G. G., Sassen, K., Wang, Z. E., Illingworth, A. J., O'Connor, E. J., Rossow, W. B., Durden, S. L., Miller, S. D., Austin, R. T., Benedetti, A., Mitrescu, C., and CloudSat Sci Team: The cloudsat mission and the a-train - A new dimension of space-based observations of clouds and precipitation, B. Am. Meteorol. Soc., 83, 1771-1790, doi:10.1175/BAMS-83-12-1771, 2002.

Stevens, B. and Feingold, G.: Untangling aerosol effects on clouds and precipitation in a buffered system, Nature, 461, 607-613, doi:10.1038/nature08281, 2009.

Swap, R., Annegarn, H., and Otter, L.: Southern African regional science initiative (SAFARI 2000): Summary of science plan, S. Afr. J. Sci, 98, 119-124, 2002.

Tanré, D., Kaufman, Y. J., Herman, M., and Mattoo, S.: Remote sensing of aerosol properties over oceans using the MODIS/EOS spectral radiances, J. Geophys. Res.-Atmos., 102, 16971-16988, 1997.
Torres, O., Bhartia, P., Herman, J., Ahmad, Z., and Gleason, J.: Derivation of aerosol properties from satellite measurements of backscattered ultraviolet radiation: Theoretical basis, J. Geophys. Res.-Atmos., 103, 17099-17110, 1998.

Torres, O., Tanskanen, A., Veihelmann, B., Ahn, C., Braak, R., Bhartia, P. K., Veefkind, P., and Levelt, P.: Aerosols and surface UV products from Ozone Monitoring Instrument observations: An overview, J. Geophys. Res.-Atmos., 112, D24S47, doi: 10.1029/2007JD008809, 2007.

Twomey, S.: Pollution and the planetary albedo, Atmos. Environ., 8, 1251-1256, 1974.

Waquet, F., Riedi, J., Labonnote, L., Goloub, P., Cairns, B., Deuzé, J., and Tanré, D.: Aerosol Remote Sensing over Clouds Using A-Train Observations, J. Atmos. Sci., 66, 2468-2480, 2009.

Wentz, F. J.: A well-calibrated ocean algorithm for special sensor microwave/imager, J. Geophys. Res.-Oceans, 102, 8703-8718, 1997.

Wielicki, B. A., Barkstrom, B. R., Harrison, E. F., Lee, R. B., Smith, G. L., and Cooper, J. E.: Clouds and the earth's radiant energy system (CERES): An earth observing system experiment, B. Am. Meteorol. Soc., 77, 853-868, 1996.

Wilcox, E. M.: Stratocumulus cloud thickening beneath layers of absorbing smoke aerosol, Atmos. Chem. Phys., 10, 1176911777, doi:10.5194/acp-10-11769-2010, 2010.

Wilcox, E. M., Harshvardhan, and Platnick, S.: Estimate of the impact of absorbing aerosol over cloud on the MODIS retrievals of cloud optical thickness and effective radius using two independent retrievals of liquid water path, J. Geophys. Res., 114, D05210, doi:10.1029/2008JD010589, 2009.

Yu, H., Kaufmann, Y. J., Chin, M., Feingold, G., Remer, L. A., Anderson, T. L., Balkanski, Y., Bellouin, N., Boucher, O., Christopher, S., DeCola, P., Kahn, R., Koch, D., Loeb, N., Reddy, M. S., Schulz, M., Takemura, T., and Zhou, M.: A review of measurement-based assessments of the aerosol direct radiative effect and forcing, Atmos. Chem. Phys., 6, 613-666, doi:10.5194/acp-6-613-2006, 2006. 